\title{
EVOLUÇÃO DO DESMATAMENTO E IMPLICAÇÕES AO USO E OCUPAÇÃO DOS SOLOS NO ENTORNO DE UNIDADES DE CONSERVAÇÃO DA AMAZÔNIA - O CASO DA FLORESTA NACIONAL DO JAMARI/RO
}

\author{
Alexis de Sousa Bastos ${ }^{(\mathrm{a}, \mathrm{b})}$, Vanderlei Maniesi ${ }^{(\mathrm{b})}$, Fabiana Barbosa Gomes $^{(\mathrm{c})}$ \\ (a) Centro de Estudos Rioterra, alexis@ rioterra.org.br \\ (b) Departamento de Geografia/Universidade Federal de Rondônia, maniesi@unir.br \\ (c) Centro de Estudos Rioterra, fabiana @ rioterra.org.br
}

Eixo: Uso e ocupação das terras e legislação ambiental

\begin{abstract}
Resumo
Compreender as relações de uso e ocupação dos solos na Amazônia, principalmente relativas ao meio físico regional, faz-se importante para subsidiar a elaboração de políticas públicas a fim evitar a repetição de problemas sociais, econômicos e ambientais ocorridos no passado. Este trabalho teve como objetivo compreender a dinâmica da antropização da Floresta Nacional do Jamari e seu entorno entre 1984 e 2013 a partir da avaliação espacial e multitemporal e implicações à ocupação e uso dos solos. Foram empregados sensores remotos para o acompanhamento multitemporal relativo aos índices de desmatamentos, bem como análise visual, classificação supervisionada e pós classificação para interpretação das imagens. Os resultados mostram significativos desmatamentos em diferentes momentos da geo-história regional, além da importância da existência de unidades de conservação na contenção do desmatamento e a necessidade de se avançar em políticas mais robustas para que as zonas de amortecimento cumpram sua efetiva função.
\end{abstract}

Palavras chave: Uso e ocupação dos solos; Unidades de conservação, Desmatamento.

\section{Introdução}

Um dos grandes desafios impostos à sociedade nacional nas últimas décadas é o de compatibilizar desenvolvimento e conservação na Amazônia (BASTOS et al., 2016). Agravam esse contexto questões relativas às mudanças climáticas de origem antrópica e o valor que tem sido dado para o papel que a maior floresta tropical do mundo desempenha nesta equação (FEARNSIDE, 2008).

Significativa parte das emissões brasileiras são oriundas de mudanças do uso da terra e florestas (BRASIL, 2014). A Amazônia desempenha dois papéis que a princípio, são considerados antagônicos: o de fronteira agrícola (BECKER, 2007, 2010) que tem consequentemente, o desflorestamento como relevante fator de emissão; e a função de ofertar serviços ambientais dentre os quais podemos destacar a ciclagem de água, conservação da biodiversidade e o armazenamento de carbono (FEARNSIDE, 2010) muitos destes confinados às unidades de conservação.

Como o desmatamento emite grandes quantidades de gases de efeito estufa, as contribuições nacionais são representativas para a mitigação do aquecimento global (SAATCHI et al., 2007). Durante a Conferência das Partes, realizada em Paris, no ano de 2015, o governo brasileiro assumiu o compromisso 
XVII Simpósio Brasileiro

de Geografia Fisica Aplicada

I Congresso Nacional

de Geografia Física

\section{OS DESAFIOS DA GEOGRAFIA FÍSICA NA FRONTEIRA DO CONHECIMENTO \\ Instituto de Geociências - Unicamp \\ Campinas - SP \\ 28 de Junho à 02 de Julho de 2017}

de reduzir até 2025 as emissões de gases de efeito estufa (GEE) em 37\% abaixo dos valores emitidos em 2005 (BRASIL, 2015). Dentre as medidas a serem adotadas pelo governo estão a implementação do Código Florestal (BRASIL, 2012) em âmbito federal, estadual e municipal e o fortalecimento das políticas que visam atingir níveis de desmatamento ilegal zero na Amazônia e compensações para supressão legal.

Após consecutivas quedas nos índices de desmatamento na Amazônia brasileira entre 2004 e 2015, o último ano, 2016, registrou aumento de 30\% nos índices desta prática ilegal, quando comparados ao período de verificação anterior (INPE, 2016). Esse aumento coloca em risco não apenas os serviços ambientais, mas espaços institucionais criados com o objetivo de resguardar tal patrimônio, como as unidades de conservação (BASTOS et al., 2015).

Rondônia, Estado situado no sudoeste da Amazônia brasileira, vive os conflitos de ter que integrar no mesmo espaço territorial o setor agropecuário, responsável pela expressiva parte do Produto Interno Bruto (RONDÔNIA, 2014), com forte demanda de crescimento, seja em área ou produtividade e ter, por outro lado, que compatibilizar tais atividades aos cerca de $40 \%$ de sua superfície destinadas à conservação sob a forma de áreas protegidas (RONDÔNIA, 2002).

Dentre estas, destaca-se o corredor ecológico formado pela Estação Ecológica (ESEC) de Samuel e Florestas Nacionais Jacundá e Jamari, por conectarem as porções oeste e leste de áreas protegidas em Rondônia. Contudo, essa região sofre, desde a década de 1980 até os dias atuais, grande pressão de atividades para mineração, pecuária, expansão da soja, criação de assentamentos da reforma agrária que tem modificado significativamente a paisagem.

Assim, esta pesquisa teve como objetivo compreender a dinâmica da antropização da Floresta Nacional do Jamari e seu entorno entre 1984 e 2013 a partir da avaliação espacial e multitemporal das formas de ocupação e as consequências destes eventos à conservação de seus recursos naturais. Compreender as complexas relações de outrora, principalmente relativas ao meio físico regional, ajudaria na proposição de políticas públicas adequadas ao uso e ocupação dos solos na região e podem evitar a repetição de problemas sociais, econômicos e ambientais ocorridos no passado (BASTOS, 2015).

\section{Materiais e métodos}

A pesquisa foi dividida em etapas de escritório para levantamento bibliográficos; laboratório para levantamento de informações e processamento; análise e interpretação de imagens e campo para validação das informações levantadas sobre o processo de uso e ocupação dos solos no entorno da UC. Com relação a escala temporal foi utilizado o recorte histórico-geográfico (SOJA, 1993) entre os anos de 1984, data de criação da unidade e 2013, período de intensas transformações sociais, econômica e ambientais da região (KOHLHEPP, 2002; BECKER, 2005). Nos trabalhos de validação em campo 
XVII Simpósio Brasileiro de Geografia Fisica Aplicada

I Congresso Nacional de Geografia Física

\section{OS DESAFIOS DA GEOGRAFIA FÍSICA NA FRONTEIRA DO CONHECIMENTO Instituto de Geociências - Unicamp Campinas - SP \\ 28 de Junho à 02 de Julho de 2017}

foram realizadas coletas de informações em 70 pontos, sendo 15 no interior da Floresta Nacional do Jamari e 55 em seu entorno (Figura 1). Utilizou-se o método de transecção em linha (SANTOS et al., 1995), no qual observações eram efetuadas todas as vezes que se percebia mudanças no ambiente ou notava-se alguma característica ambiental considerada importante.
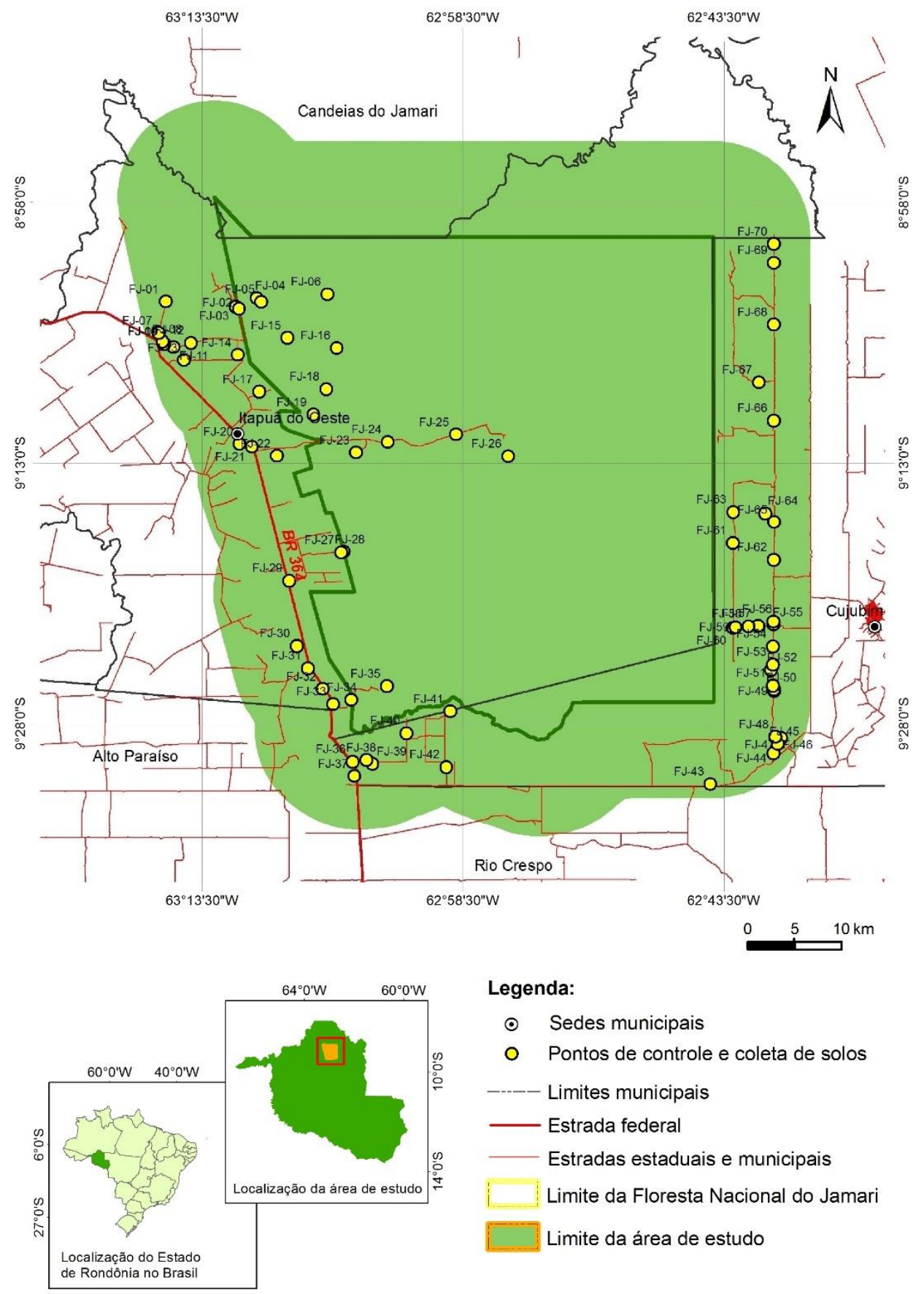

Legenda:

$\odot$ Sedes municipais

- Pontos de controle e coleta de solos

---- Limites municipais

- Estrada federal

- Estradas estaduais e municipais

Limite da Floresta Nacional do Jamari

Limite da área de estudo

Base de Dados: IBGE 2007/ ICMBIO 2010/ RONDÔNIA 2002 Datum: SIRGAS 2000

Figura 1. Mapa de localização da área de estudo e pontos de validação de informações que engloba a Flona do Jamari e um raio de $10 \mathrm{~km}$ em seu entorno delimitada a partir da linha de demarcação ofícial (BRASIL, 2000). 


\subsection{Localização e características do meio físico na área de estudo}

A área de estudo compreende a Floresta Nacional (Flona) do Jamari e uma faixa de 10 quilômetros em seu entorno, contados a partir da linha demarcatória oficial decretada pelo governo federal (BRASIL, 2000), totalizando 461.772 hectares. A Flona do Jamari localiza-se no norte rondoniense (Figura 1). Está compreendida entre as longitudes $62^{\circ} 44^{\prime} 05^{\prime \prime}$ e 6316'54" W e latitudes $9^{\circ} 00^{\prime} 00^{\prime \prime}$ e $9^{\circ} 30^{\prime} 00^{\prime \prime} \mathrm{S}$.

A unidade possui 223.086,27 hectares e foi criada pelo Decreto $\mathrm{n}^{\circ}$ 90.224, de 25.09.1984 (BRASIL, 1984). Limita-se ao norte com a Estação Ecológica (ESEC) de Samuel. O principal acesso à Flona do Jamari é realizado a partir de Porto Velho, por via terrestre pela BR-364, percorrendo-se $110 \mathrm{~km}$ de distância sentido Cuiabá.

A Floresta Nacional do Jamari está inserida na unidade estrutural cratônica (QUADROS et al., 2011) Sul-Amazônica da Plataforma Sul Americana, em região estabilizada geotectonicamente no Neoprotezoroico (PIRES, 2009). Dados geológicos de Scandolara et al. (1999) evidenciam que a área está assentada em sua totalidade porção sobre rochas Paleoproterozoicas do Complexo Jamari. Possui áreas com formações Neoproterozoicas dos Granitos Jovens de Rondônia com maior evidência na parte sudeste da área. Também pode-se notar a presença de coberturas constituídas por sedimentos indiferenciados Cenozoicos (QUADROS, 2010).

Foram identificadas cotas que variam entre 100 e 300 m e notabilizam-se pela ocorrência de extensas áreas aplainadas, levemente entalhadas pela rede de drenagem (RADAMBRASIL, 1978), estando frequentemente recobertas por coberturas detritolateríticas parcialmente desnudadas, gerando baixos platôs lateríticos (ADAMY, 2002) como pode ser visto nas porções oeste e nordeste da área.

As médias de temperatura anual e pluviosidade variam de $24^{\circ} \mathrm{C}$ a $26^{\circ} \mathrm{C}$ e entre $2.400 / 2.600 \mathrm{~mm} / \mathrm{ano}$ (GAMA, 2002), respectivamente. Com relação aos solos predominam os Latossolos (RADAMBRASIL, 1978; RONDÔNIA, 2002), sendo o de maior abrangência da área o Latossolo Amarelo Distrófico (RADAMBRASIL, 1978; RONDÔNIA, 2002), considerado de escassa fertilidade devido à deficiência de nutrientes tais como fósforo, potássio e cálcio (FORTUNA, 1988).

A fitofisionomia mais representativa na área de estudo é a Floresta Ombrófila Aberta Submontana (RADAMBRASIL, 1978; SILVA \& VINHA, 2002), que ocupa 95\% da unidade (BRASIL, 2005). Essa formação está adaptada e diretamente ligada a solos com características quartzosas formados no Quaternário (RONDÔNIA, 2002).

\subsection{Sensoriamento remoto}


XVII Simpósio Brasileiro

de Geografia Fisica Aplicada

I Congresso Nacional

de Geografia Física
OS DESAFIOS DA GEOGRAFIA FÍSICA NA FRONTEIRA DO CONHECIMENTO

Instituto de Geociências - Unicamp

Campinas - SP

28 de Junho à 02 de Julho de 2017

Os trabalhos de interpretação, processamento e análise de imagens tiveram os procedimentos a seguir.

Além da análise visual (FLORENZANO, 2002) foi realizada a comparação entre "pixels", textura e cores (PERROTTA, 2005), que permitiu a extração de informações sobre a Geologia como identificação dos limites das áreas com rochas graníticas. Os sensores remotos permitiram obter informações sobre a Geomorfologia como rugosidade das redes de drenagem e da vegetação, áreas florestadas e não florestadas (CAMARGO et al., 2004) e serviram para corroborar informações de impactos antrópicos relacionados ao desmatamento verificados em campo.

As imagens também possibilitaram a realização do acompanhamento multitemporal $(1984,1994,2004$ e 2013) conforme Alves et al. (1996) relativo aos índices de desmatamentos a partir da criação da Flona em 1984. Nesta ação foi utilizado o método de comparação de "pixels" por máxima verossimilhança (SMIATEK, 1995) na obtenção de dados sobre desmatamentos, acúmulo decenal e suas quantificações através de tratamentos estatísticos realizados através do programa Envi 4.7.

Todas as imagens, exceto a referente ao ano de 2013, foram obtidas gratuitamente na Divisão de Geração de Imagens - DGI/INPE, no endereço <http://www.dgi.inpe.br/siteDgi/index_pt.php>. Foram utilizadas imagens do satélite LANDSAT 5 da cena correspondente a órbita e linha 232-66, do sensor Thematic Mapper - TM. Para os estudos referentes ao ano de 2013 foram adquiridas imagens gratuitas no site <http://earthexplorer.usgs.gov> do Serviço Geológico dos EUA (USGS), do satélite LANDSAT 8, da cena correspondente a órbita e linha 232-66, do sensor Operacional Terra Imager (OLI).

\subsubsection{Tratamento de imagens}

O primeiro tratamento consistiu no registro das cenas - método utilizado para corrigir as coordenadas de uma imagem de satélite através de locação de pontos de controle - onde foram usadas referências com coordenadas conhecidas e transferidas a uma cena não registrada (PERROTTA, 2005). O método utilizou as cena do ano de 2013 como referência para o registro das demais, considerando que a mesma é registrada. Para isto utilizou-se o sistema de processamento de imagens ENVI 4.7.

Após registro, foram selecionadas as bandas 5(R), 4(G) e 3(B) de cada cena dos anos de 1984, 1994 e

2004 (ALVES et al., 1996; SHIMABUKURO et al., 1999) e bandas 6, 5 e 4 do ano de 2013 para composição colorida através do processo denominado de "Layer Stacking" (empilhamento de bandas) e resultou em uma composição utilizada para análise de vegetação e desmatamento-(OLIVEIRA, 1999; PERROTTA, 2005). Nenhum contraste foi efetuado na imagem original. As imagens foram juntadas por um processo denominado Mosaico de Cenas (CREPANI et al., 2002). 


\subsubsection{Análise e interpretação das imagens de satélite}

A análise dos vetores de antropização foi realizada através de interpretação visual das imagens de satélite (FLORENZANO, 2002), a partir da série histórica entre 1984 e 2013. O objetivo foi quantificar a perda de cobertura florestal por desmatamento e alagamentos (hidrelétricas e piscicultura).

Para obtenção de dados sobre perda de cobertura florestal da área de estudo foi feito pela classificação supervisionada de imagens através do algorítmo de classificação Maximum Likelihood (SMIATEK, 1995; ORTIZ \& FREITAS, 2005). Foram definidas as seguintes classes: a) desflorestamento; b) floresta; c) água; e d) afloramento rochoso.

Foi necessária a definição de classes em "Regions of Interest-ROI", Regiões de Interesse ou Área de Treinamento (PAL \& PAL, 1993). Levou-se em consideração elementos como forma, tamanho, cor e padrões de "pixels" para identificar diferenças nas imagens. O produto gerado passou por processo de pós-classificação submetendo a classificação obtida ao tratamento do algoritmo "Majority Analysis“ (PASSO et al., 2013). Esse método possibilitou identificar como os movimentos colonizatórios avançaram sobre a região ao longo dos anos e permitiu identificar perda florestal por alagamento.

\section{Resultados e Discussões}

\subsection{Desmatamento da área de estudo até 1984}

Em 1984, ano de criação da Floresta Nacional do Jamari, o entorno da unidade de conservação começava a ser ocupado por atividades que demandavam supressão florestal. Em suas porções norte e leste, havia inexistência de sinais de ocupação, conforme Figura 2A. Entretanto, em sua porção oeste, próxima a BR-364, evidenciavam-se indícios de antropização causados pelo contato com a estrada. Nota-se que ao sul na divisa entre os municípios de Cujubim e Rio Crespo (até então inexistentes), ocorriam inícios de desmatamentos e ao contrário, ao sudeste da área, já se evidenciavam desmatamentos significativos.

Outro fato importante que a imagem da Figura $2 \mathrm{~A}$ permite notar é a conexão entre estrada e desmatamento. A partir dela irradia-se o processo de ocupação. Sendo a BR-364 a única via de penetração terrestre no estado, as áreas próximas a ela foram as primeiras a receber fortes fluxos de imigrantes. Mesmo que em 1984 os índices de desmatamentos não fossem relativamente elevados para a área e ocorressem somente junto ao eixo da BR-364, a forma de ocupação e seus vetores preconizavam um iminente avanço dos valores referentes a perda de cobertura florestal, como pode ser percebido nas imagens nos decênios seguintes (Figuras 2B, 2C e 2D). 
XVII Simpósio Brasileiro de Geografia Fisica Aplicada

I Congresso Nacional de Geografia Física

\section{OS DESAFIOS DA GEOGRAFIA FÍSICA NA FRONTEIRA DO CONHECIMENTO \\ Instituto de Geociências - Unicamp Campinas - SP \\ 28 de Junho à 02 de Julho de 2017}

Nota-se que o modelo de ocupação ortogonal funcionou no sentido de interiorizar cada vez mais as ações do desmatamento, pois favoreceu a ocupação de novas áreas próximas às linhas, retroalimentando os processos de interiorização. Esse modelo de ocupação era agravado por dois fatores que causavam interiorização mais acentuada e desmatamentos recorrentes: a) na época, a disponibilidade de espaço permitia um modelo de assentamento com grandes áreas contíguas e lotes com dimensões de mais de mil hectares destinados a um único assentado; e b) o indicador do INCRA para avaliar o uso da terra e titular os proprietários era o percentual de área desmatada (50\% para demonstração de posse).

A imagem mostra que havia três grandes desmatamentos no interior da unidade realizados para fins de mineração. Um próximo ao limite norte, outro a oeste e um terceiro na porção central da área. Em 1984 a porção oeste era a mais impactada por fragmentação florestal e seus efeitos. Outros dois desmatamentos menores podem ser visualizados no sul da Flona e a sudoeste, próximo aos limites da unidade. Estes decorrem de atividades de garimpo. Houve perda de 1.983 hectares de cobertura florestal por alagamento na porção noroeste da área para fins minerários. Ao todo foram desmatados até 1984 aproximadamente 15.582 hectares.

\subsection{Desmatamento da área de estudo entre 1984 e 1994}

No ano de 1994, os avanços das frentes de colonização oriundas do processo de ocupação da região podem ser amplamente notados. Com exceção do limite ao norte, área destinada a criação da Estação Ecológica de Samuel, unidade de proteção integral criada para compensar os efeitos de implantação da Usina Hidrelétrica de Samuel (a noroeste da área). As porções oeste, sul, sudeste e leste passaram a ser intensamente ocupadas, Figura 2B. 


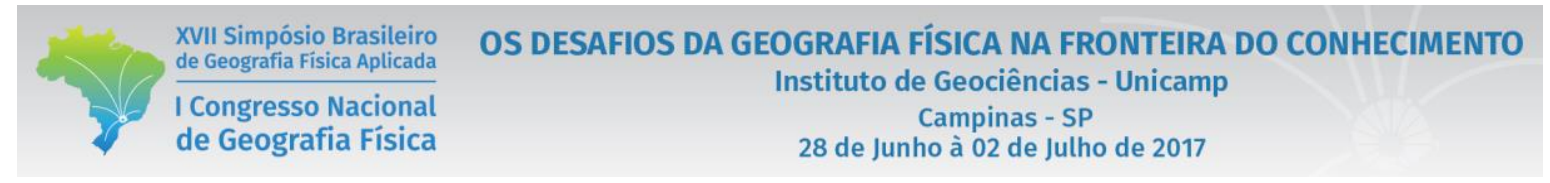
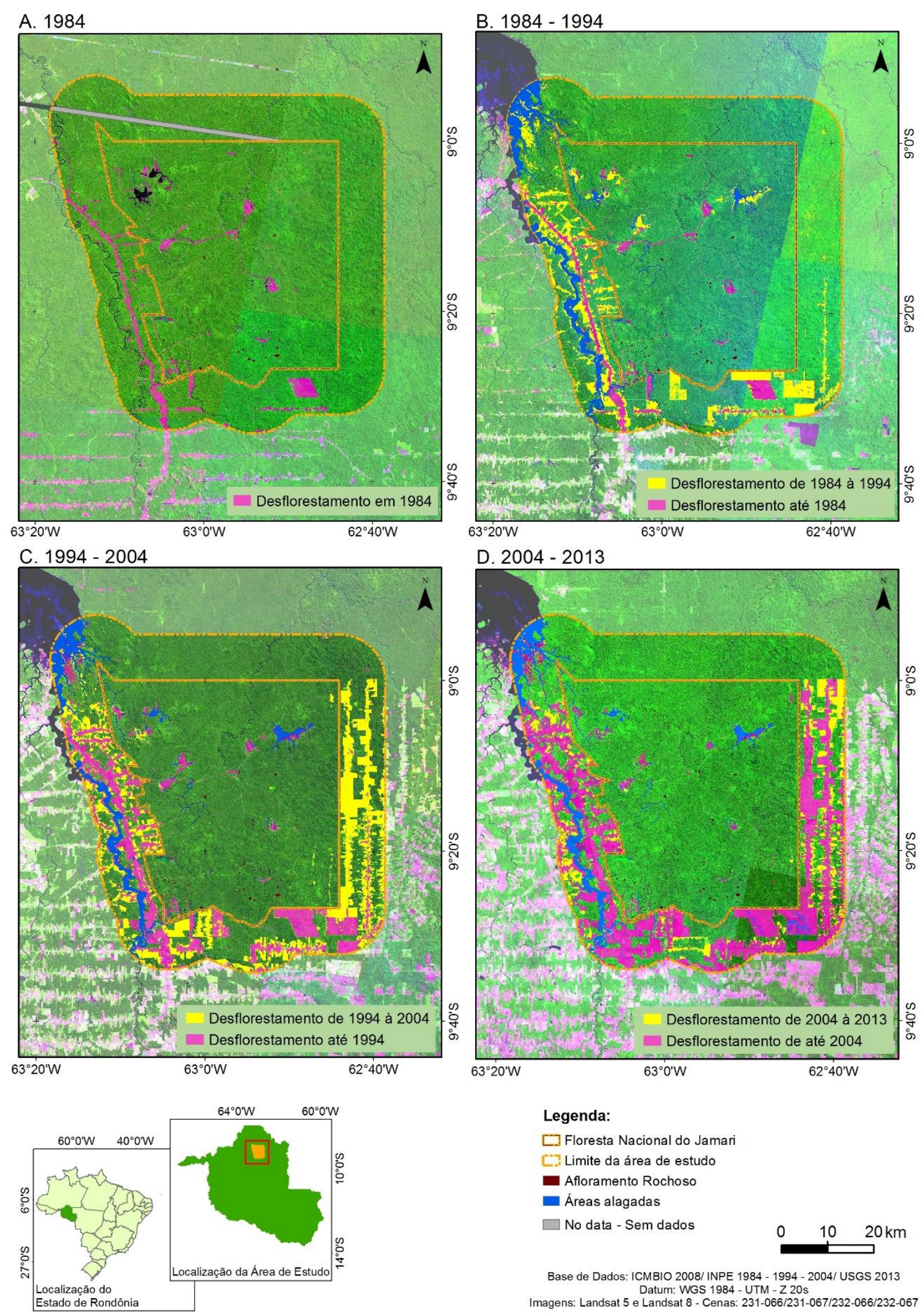

Figuras 2A, 2B, 2C e 2D. Cartas imagem contendo os desmatamentos na área de estudo entre os anos de $1984 \mathrm{e}$ 2013. 
XVII Simpósio Brasileiro

de Geografia Fisica Aplicada

I Congresso Nacional

de Geografia Física
OS DESAFIOS DA GEOGRAFIA FÍSICA NA FRONTEIRA DO CONHECIMENTO

Instituto de Geociências - Unicamp

Campinas - SP

28 de Junho à 02 de Julho de 2017

A unidade de conservação (UC) que deveria funcionar como um limitador às frentes de desmatamento cumpre parcialmente sua função. A área a sudeste da UC, onde havia o maior desmatamento contíguo em 1984, passa a ser ocupado e novas frentes de ocupação avançam sobre os limites da área protegida. No período do decênio que compreende os anos entre 1984 e 1994 os assentamentos criados a oeste, sul e leste da unidade, em Itapuã do Oeste, Projeto de Assentamento (PA) Vale do Jamari e Cujubim, PAs Cujubim I e II, Américo Ventura, Renascer e Agostinho Becker produziram os efeitos do modelo de ocupação alicerçado no desmatamento como forma de mostrar posse. Aliado a carência de tecnologias e conhecimentos condizentes com as capacidades de suporte dos ambientes e suas potencialidades de produção impulsionaram os índices de desmatamentos em seu entorno.

A instalação da usina hidrelétrica de Samuel colaborou para o aumento das ocupações. Além da perda de cobertura florestal por alagamento para usina hidrelétrica (16.502,76 hectares), nota-se também no interior da UC a ampliação de áreas de mineração, sobretudo em sua porção nordeste com a ampliação de áreas alagadas para extração de bens minerais.

As linhas demarcatórias da área protegida ficam mais evidentes com o crescimento dos vetores de antropização ao oeste, sul e a leste. As possibilidades de uso do espaço para produção através de expansão tornam-se cada dia mais restritivos. Em 1994, mesmo tendo sido ilegalmente invadida na parte sudeste, a UC funcionava como uma contenção aos avanços das frentes de desmatamento. O simples fato de haver uma demarcação oficial, apesar das deficiências do Estado para fiscalizar as áreas, fez com que a maioria da população respeitasse seus limites. Esse dado é corroborado por Ferreira et al. (2005), que aponta não somente as unidades de conservação, mas também as terras indígenas como uma importante ferramenta para conter ou diminuir os processos de desmatamento na Amazônia.

Como pode ser visto na Figura 2B entre 1984 e 1994 houve um incremento de 30.140 hectares desmatados, totalizando 45.722 hectares desmatados em duas décadas.

\subsection{Desmatamento da área de estudo entre 1994 e 2004}

Entre os anos de 1994 e 2004 é possível visualizar os maiores avanços das frentes de desmatamento no entorno da UC e proximidades, Figura 2C. O entorno da unidade é cortado por propriedades rurais de diferentes tamanhos, mas em sua maioria de pequenos produtores, como pode ser observado pela textura da imagem e seu padrão de desmatamento. Expressiva porção da faixa no entorno da unidade a Oeste, Sul e Leste é ocupada, principalmente para fins de pecuária bovina como constatado por Bastos et al. (2016). A exceção se dá na porção Norte, devido a Estação Ecológica de Samuel.

Destaca-se nesse intervalo a emancipação político administrativa do município de Cujubim, ocorrida em 1994, e o forte processo de emigração no Estado por famílias se reorganizando internamente. No 
XVII Simpósio Brasileiro

de Geografia Fisica Aplicada

Congresso Nacional

de Geografia Física

\section{OS DESAFIOS DA GEOGRAFIA FÍSICA NA FRONTEIRA DO CONHECIMENTO \\ Instituto de Geociências - Unicamp \\ Campinas - SP \\ 28 de Junho à 02 de Julho de 2017}

final dos anos 1990 Cujubim viria a se tornar um dos maiores produtores de madeira de Rondônia. A instalação de assentamentos e teoricamente "terras sendo beneficiadas", a existência de unidades de conservação nas imediações e de terras devolutas funcionaram como fortes indutores para atração de frentes de exploração ilegal de madeira. No início dos anos 2000 o município de Cujubim respondeu por mais da metade do volume de madeiras comercializado em Rondônia. Almeida Silva et al. (2009) contabilizou a existência de 88 serrarias na localidade.

Cujubim é um exemplo do que Schneider et al. (2000) chamaram de padrão "boom-colapso". Um aumento a curto dos indicadores econômicos (Produto Interno Bruto - PIB e emprego) favorecido pela geração de renda e atração de imigrantes. Segundo os autores, esse padrão também é caracterizado pelos elevados custos de degradação dos recursos naturais bem como aumento da violência e, no longo prazo, as regiões muito desmatadas apresentam redução nas taxas de violência e indicadores socioeconômicos inferiores às regiões onde o desmatamento está acontecendo.

O entorno da UC só não está completamente desmatado devido a necessidade da manutenção das reservas legais, conforme preceitua o Código Florestal.

Chama a atenção o fato de não haver expansão das áreas destinadas à mineração ou garimpagem no interior da Flona. Esse fator pode explicar a diminuição dos valores de perda de cobertura florestal por alagamento que em comparação com a década anterior, 1984-1994, apresentou uma redução de 1,75\%, equivalente a 288 hectares.

Contudo, entre os anos de 1994 e 2004 em que já se contabilizava 45.722 hectares desmatados, houve um incremento de desmatamento de 47.036 hectares aproximadamente. O decênio 1994-2004 foi o que mais desflorestamento produziu entre os analisados. Ou seja, desmatou-se mais em uma década que em toda a história regional anterior.

\subsection{Desmatamento da área de estudo entre 2004 e 2013}

Durante os anos de 2004 a 2013 ocorreram as menores taxas relativas de desmatamento entre os decênios analisados referentes a formas de uso e ocupação dos solos no entorno da Flona do Jamari.

Notam-se poucos avanços das frentes de desmatamento no entorno da unidade de conservação, uma vez que a ocupação da região parece ter sido consolidada no final dos anos 1990, início dos anos 2000 e devido ao lançamento, em 2004, do Plano de Ação para a Prevenção e Controle do Desmatamento na Amazônia Legal - PPCDAM como resposta governamental às crescentes taxas de desmatamento na Amazônia. Não há sinais de novas áreas destinadas à mineração no interior da UC ou locais impactados por garimpagem em seu entorno (Figura 2D). 
XVII Simpósio Brasileiro

de Geografia Fisica Aplicada

I Congresso Nacional

de Geografia Física

\section{OS DESAFIOS DA GEOGRAFIA FÍSICA NA FRONTEIRA DO CONHECIMENTO \\ Instituto de Geociências - Unicamp \\ Campinas - SP \\ 28 de Junho à 02 de Julho de 2017}

Contudo, é perceptível o aumento da perda de área por alagamento na porção sul da área, devido a instalação de tanques escavados para piscicultura. Esta é a "mais nova" atividade econômica induzida por políticas públicas de crédito e preconizadas pelos governantes como a vocação da Amazônia e como alternativa aos pequenos proprietários frente a impossibilidade da pecuária. Durante este decênio (20042013) houve um aumento de 1.087 hectares se comprado com o anterior, totalizando 17.879 hectares alagados.

A existência da unidade de conservação funcionou até 2013 como um limitador às frentes de desmatamento. Mesmo estando em uma área voltada à produção mineral, florestal, agrícola e pecuária a Flona manteve a cobertura vegetal dentro de seus limites. Entretanto, a situação no entorno é de um ambiente altamente impactado, tendo perdido quase $50 \%$ de sua cobertura florestal por desmatamento para fins agrícolas ou, mais recentemente, por alagamento para piscicultura.

\section{Conclusões}

A criação da unidade de conservação colaborou para a diminuição dos índices de desmatamento, principalmente no interior da área. Contudo, sua zona de amortecimento foi severamente impactada, evidenciando que essa faixa, embora seja prevista pela legislação como de uso restrito, não é percebida como tal, seja pelos gestores, seja pela população.

Os índices de desmatamento cresceram com a instalação de assentamentos da reforma agrária e emancipação dos municípios de Itapuã do Oeste e Cujubim de 1984 a 2004, bem como decresceram a partir de 2004 devido a consolidação das áreas e a programas de contenção de desmatamento realizados pelo governo federal no âmbito do PPCDAm.

\section{Agradecimentos}

Petrobras pelo patrocínio através do Programa Petrobras Socioambiental.

\section{Bibliografia}

ALMEIDA SILVA, A.; BASTOS, F.; BASTOS, A.S.; GOMES, F.B. Análise socioeconômica do entorno da área de concessão pública UMF III na Floresta Nacional do Jamari. Porto Velho, Centro de Estudos Rioterra, 2009.

ALVES, D.S.; KALIL, E.M.; MOREIRA, J.C.; ORTIZ, J.O. SOARES, J.V.; FERNANDEZ, O.; ALMEIDA, S. Characterizing land use dynamics in Amazon using multi-temporal imagery and segmentation techniques. In: International Archives of Photogrammetry and Remote Sensing, 31 (B7), 1996.

ADAMY, A. Estudos das formas de relevo. In: Atlas Geoambiental de Rondônia. Porto Velho: SEDAM, 2002. 
XVII Simpósio Brasileiro

de Geografia Fisica Aplicada

Congresso Nacional

de Geografia Física
OS DESAFIOS DA GEOGRAFIA FÍSICA NA FRONTEIRA DO CONHECIMENTO

Instituto de Geociências - Unicamp

Campinas - SP

28 de Junho à 02 de Julho de 2017

BASTOS, A. Zonas de aptidão agrícola como subsídio ao ordenamento territorial no entorno de unidades de conservação da Amazônia: o caso da Floresta Nacional do Jamari/RO. Tese de Doutorado, Universidade Federal do Paraná/UFPR, 256 p., 2015.

BASTOS, A.S; MANIESI, V.; GOMES, F.B. Vulnerabilidade natural à erosão no Sudoeste da Amazônia associada aos seus modos de ocupação? O caso do entorno da Terra Indígena Uru Eu Wau Wau. Revista Brasileira de Geomorfologia, v.16, p. 271-282, 2015.

BASTOS, A.S; MANIESI, V.; GOMES, F.B. Ordenamento territorial na Amazônia: implicações físicas e químicas como fatores limitantes ao uso e ocupação dos solos. Saarbrücken, Alemanha. Novas Edições Acadêmicas, 2016.

BECKER, B. Amazônia: geopolítica na virada do III milênio. Rio de Janeiro, Garamound, 2007.

BECKER, B. Novas territorialidades na Amazônia: desafio às políticas públicas. Boletim do Museu Paraense Emilio Goeldi de Ciências Humanas, 5 (1), p.17-23, 2010.

BRASIL. Decreto $n^{\circ} 90.224$ de 25 de setembro de 1984. Cria a Floresta Nacional do Jamari, no Estado de Rondônia, e dá outras providências. Diário Oficial da União, Brasília, DF, 1984. Disponível em: <http://legis.senado.gov.br/legislacao/ListaTextoIntegral.action?id=105812\&norma=128982〉. Acesso em: 08 ago. 2015

BRASIL. Ministério do Meio Ambiente. Lei no 9.985/2000. Regulamenta o art. 225, § 1丷ㅡㄹ incisos I, II, III e VII da Constituição Federal, institui o Sistema Nacional de Unidades de Conservação da Natureza e dá outras providências, 2000.

BRASIL - Ministério do Meio Ambiente. Plano de manejo da Floresta Nacional do Jamari. Brasília, IBAMA, 2005

BRASIL. Lei no 12.651 de 25 de maio de 2012. Dispõe sobre a Proteção da vegetação nativa e dá outras providências. Diário Oficial da União, Brasília, DF, 2012. Disponível em:

<http://www.planalto.gov.br/ccivil_03/_ato2011-2014/2012/lei/112651.htm〉. Acesso em: 01 fev. 2017.

BRASIL - Ministério da Ciência, Tecnologia e Inovação. Estimativas anuais de emissões de gases de efeito estufa no Brasil. Brasília, 2014.168p.

BRASIL. Intentended nationally determined contribution. Towards achieving the objective of the United Nations framework convention on climate change. Paris, 2015. Disponível em:

< http://unfccc.int/focus/indc_portal/items/8766.php >. Acesso em: 06 fev. 2017.

CAMARGO, E.C.G.; FUCKS, S.D.; CÂMARA, G. Análise espacial de superfícies. In: Análise espacial de dados geográficos. Druck, S.; Carvalho, M.S.; Câmara, G.; Monteiro, A.V.M. (eds.). Brasília, Embrapa, 2004.

CREPANI, E.; DUARTE, V.; SHIMABUKURO, Y.E.; FIDALGO, E.C.C. Sensoriamento remoto e geoprocessamento no mapeamento regional da cobertura e uso atual da terra. Geografia, 27(1), p.119-135, 2002.

FEARNSIDE, P.M. Mudanças climáticas globais e a floresta Amazônica. In: Biologia e as mudanças climáticas globais no Brasil. Buckeridge, M.S. (ed.). São Paulo, RiMa Editora, p.131-150, 2008.

FEARNSIDE, P.M. Estoques e fluxos de carbono na Amazônia como recursos naturais para geração de serviços ambientais. In: Buenafuente, S.M.F. Amazônia: dinâmica do carbono e impactos socioeconômicos e ambientais. Boa Vista/RR: Editora da Universidade Federal de Roraima, p.27-56, 2010.

FLORENZANO, T.G. Imagens de satélite para estudos ambientais. São Paulo, Oficina de Textos, 2002.

FORTUNA, A. Caracterização dos trópicos úmidos brasileiros. In: Hébette, J. (coord). Natureza, tecnologia e sociedades. Belém: NAEA, p.7-13, 1988.

GAMA, M.J. Clima. In: Atlas geoambiental de Rondônia. Porto Velho, SEDAM, 2002.

INPE - INSTITUTO NACIONAL DE PESQUISAS ESPACIAIS. Projeto PRODES de monitoramento da floresta amazônica brasileira por satélite. Taxas anuais 2004-2016, 2016. Disponível em: < http://www.obt.inpe.br/prodes/index.php>. Acesso em: 05 fev. 2017.

KOHLHEPP, G. Conflitos de interesse no ordenametno territorial da Amazônia brasileira. Estudos Avançados, 16 (45), p.37-61, 2002.

OLIVEIRA, H.N.B. Segmentação e classificação de imagens Landsat. Dissertação de Mestrado, Universidade Federal do Paraná/UFPR, 1999. 
ORTIZ, J.L.; FREITAS, M.I.C. Mapeamento do uso da terra, vegetação e impactos ambientais por meio de sensoriamento remoto e geoprocessamento. Geociências, 23 (1), p.91-104, 2005.

PAL, N.R.; PAL, S.K. A review on image segmentation techniques. Pattern Recognition, 26 (9), p.1277-1294, 1993.

PASSO, D.P.; BIAS, E.S.; BRITES, R.S.; COSTA, G.A.O.P. Uso do sistema interimage para identificação de alvos urbanos em imagens de satélite worldview II. Revista Brasileira de Cartografia, 65 (6), p.1211-1221, 2013

PERROTA, M.M. Registro de imagens com relação ao mosaico geocover 2000. Divisão de Sensoriamento Remoto-CPRM, 2005.

PIRES, F.R.M. Arcabouço geológico. In: Geomorfologia do Brasil. Cunha, S.B.C.; Guerra, A.J.T. (orgs.), 5.ed., Rio de Janeiro, Bertrand Brasil, p.17-69, 2009.

QUADROS, M.L.E.S. Contexto geológico. In: Geodiversidade do estado de Rondônia. Adamy, A. (org.), Porto Velho, CPRM, 2010.

QUADROS, M.L.E.S.; PALMEIRA, L.C.M.; CASTRO, C.C. Geologia e recursos minerais da folha rio Machado (SC.20-X-C). Escala 1:250.000. Porto Velho: CPRM, 2011

RADAMBRASIL. Levantamento de recursos naturais. Projeto RADAMBRASIL, Folha SC.20 - Porto Velho. DNPM, 1978.

RONDÔNIA. SEPLAD/PLANAFLORO/PNUD.BRA/00/004. As unidades de conservação de Rondônia. 2.ed., Porto Velho, 2002.

RONDÔNIA. Secretaria de Planejamento, Orçamento e Gestão. Produto interno bruto (PIB) do estado de Rondônia 2002-2012. Porto Velho, 2014. Disponível em:

<http://www.seplan.ro.gov.br/Uploads/Arquivos/PDF/PIBRondonia/PRODUTO\%20INTERNO\%20BRUTO\%2 02012-.pdf >. Acesso em: 05 fev. 2017.

SAATCHI, S.S.; HOUGHTON, R.A.; SANTOS AVALA, R.C.; SOARES, J.V.; YU, Y. Spatial distribution of aboveground live biomass in amazon basin. Global Change Biology. 13, p. 816-837, 2007.

SANTOS, H.G.; HOCHMÜLLER, D.P.; CAVALCANTI, A.C.; RÊGO, R.S.; KER, J.C.; PANOSO, L.A.; AMARAL, J.A.M. Procedimentos normativos de levantamentos pedológicos. Brasília: Embrapa - SPI, 1995.

SCANDOLARA, J.E.; RIZZOTO, G.J.; AMORIM, J.L.; BAHIA, R.C.B.; QUADROS, M. L.; SILVA, C.S. Mapa geológico de Rondônia na escala de 1:1.000.000, CPRM, Porto Velho, RO, 1999.

SCHNEIDER, R.R.; ARIMA, E.; VERÍSSIMO, A.; BARRETO, P.; SOUZA Jr. C. Amazônia sustentável: limites e oportunidades para o desenvolvimento rural. Belém: Imazon, 2000.

SHIMABUKURO, Y.E.; DUARTE, V.; SANTOS, J.R.; MELLO, E.M.K.; MOREIRA, J.C. Levantamento de áreas desflorestadas na Amazônia através de processamento digital de imagens orbitais. Floresta \& Ambiente, $6(1)$, p.38-44, 1999.

SILVA, R.B.; VINHA, E. Vegetação: biodiversidade de espécies florestais. In: Atlas Geoambiental de Rondônia. Porto Velho, SEDAM, 2002.

SMIATEK, G. Sampling Thematic Mapper Imagery for Land Use Data. Remote Sensing of Environment , 52, p.116-121, 2005.

SOJA, E.W. Geografias pós-modernas: a reafirmação do espaço na teoria social. Rio de Janeiro: Jorge Zahar Ed., 1993. 